\title{
Social Navigation
}

\section{AND THE RESETTLEMENT EXPERIENCES of Separated Children in Canada}

\author{
Myriam Denov and Catherine Bryan
}

\begin{abstract}
This article explores the implications of language and discourse for the experiences of separated refugee children in Canada, and the ways in which anti-refugee and anti-child discourses shape the terrain of resettlement. The article begins by tracing the academic and popular discourses of refugee populations generally, and separated children specifically. Given the formulaic and rigid portrayals and representations, we introduce the concept of social navigation, which provides a useful framework to study the resettlement experiences of separated children. Following an overview of the study's methodology, we explore the social navigation and resettlement experiences of seventeen youth. In particular, we highlight the creative, resourceful, and thoughtful ways in which the youth navigated the refugee determination system, experiences of discrimination and isolation, as well as separation and loss during the resettlement process. The article ultimately underscores the ways in which these children and youth strategically navigate resettlement, overcome challenges, and-despite signifcant ideological barriers and material obstacles-ensure their survival and well-being as individuals and as groups.
\end{abstract}

\begin{abstract}
Résumé
Cet article explore les implications de la langue et $d u$ discours pour les expériences des enfants réfugiés séparés au Canada et comment le discours anti-réfugiés et antienfants façonne le terrain de la réinstallation. L'article retrace d'abord les discours savants et populaires des populations de réfugiés en général, et en particulier des enfants séparés. Étant donnédes descriptions et des représentations stéréotypées et rigides, nous introduisons le concept de la navigation sociale qui fournit un cadre utile pour étudier les expériences de réinstallation des enfants séparés. Après un survol de la méthodologie de l'étude, nous explorons la navigation sociale et les expériences de réinstallation de dix-sept jeunes réfugiés. En particulier, nous soulignons les moyens imaginatifs, débrouillards et réfléchis par lesquels les jeunes évoluent dans le système de détermination $d u$ statut de réfugié, les expériences de discrimination et d'isolement, ainsi que la séparation et la perte au cours $d u$ processus de réinstallation. L'article souligne finalement la façon dont ces enfants et adolescents naviguent stratégiquement la réinstallation, surmontent des difficultés, et, malgré d'importantes barrières idéologiques et obstacles matériels, assurent leur survie et bien-être en tant qu'individus et en tant que groupes.
\end{abstract}


Most [refugees] are smuggled in or are queue-jumpers who lie their way into the country. - Hazel McCallion, mayor of Mississauga, Ontario ${ }^{1}$

This legislation will help stop foreign criminals, human smugglers and those with unfounded refugee claims from abusing Canada's generous immigration system and receiving taxpayer-funded health and social benefits. -Jason Kenney, minister of immigration ${ }^{2}$

Let me be free and give me equal opportunities, and I will show you what I can do. -Akin, separated refugee youth from Ethiopia

\section{Introduction}

Contrary to being a neutral medium of expression, language and discourse serve to construct unequal identities with differential material consequences, empowering and privileging some as legitimate and normative, while subordinating and rendering others as delegitimized. ${ }^{3}$ Highlighting the power of discourse and representation, Kellner suggests that Western discourses and media depictions are neither impartial nor insignificant to the ongoing construction and entrenchment of Western thought, values, and identity. ${ }^{4}$ Rather, reflecting the power of "meaning, metaphors, representations, images, stories, [and] statements,"5 they inform understandings of "deviance" and "normalcy," "pathology" and "health," and "deserving" and "undeserving." 6 And as such, they "provide [the] materials out of which we forge our very identities, our sense of selfhood; our notion of what it means to be male or female; our sense of class, of ethnicity and race, of nationality, of sexuality, of 'us' and 'them."'7 Determining the parameters of belonging, discourse and language interact with and inform the practices and structures that are lived out in society from day to day, ${ }^{8}$ delimiting issues that merit attention, as well as the populations that can legitimately claim aid and access social services. Despite the precariousness of their lives and experiences, ${ }^{9}$ separated asylum-seeking and refugee children, who are the focus of this article, are vulnerable to the often exclusionary consequences of these discourses and processes. Yet, as we argue here, these processes and discourses do not unilaterally determine or constrain these youth. Instead, as demonstrated by the young people in our sample, separated asylum-seeking and refugee children actively and thoughtfully navigate the uneven terrain of resettlement, overcoming considerable obstacles, both ideological and material.

The Office of the United Nations High Commissioner for Refugees (UNHCR) defines a separated child as "a person who is under the age of eighteen years, unless, under the law applicable to the child, majority is attained earlier and who is separated from both parents and is not being cared for by an adult who law or custom has the responsibility to do so."10 The UNHCR also estimates that of the 57.4 million people currently displaced, half are children, and that millions of these children have been separated from both parents and adults otherwise legally and/or culturally designated to care for them. ${ }^{11}$ Each year, a small but growing number of children will seek asylum under these conditions in industrialized countries, and in Canada it is estimated that approximately 300 separated children arrive each year. ${ }^{12}$

These 300 young people represent one of two principle categories of separated refugee children in Canada. Like other asylum-seekers, they request asylum upon arrival in Canada, either at the border or inland. And while this is their right (as mandated by both Canadian and international refugee protection law), ${ }^{13}$ their legal status and standing in Canada is tenuous, contingent upon a successful refugee determination process and mediated largely by the supportive services they are able to access (or not). The second group of separated children are those who arrive via the Government-Assisted Refugee (GAR) Program. These young people arrive as refugees and, as such, are permanent Canadian residents with the rights and privileges thereof. Since 2001, however, a moratorium has restricted the settlement of separated children who do not have family in Canada. Both groups face considerable challenges upon arrival, and while the former must contend with the inconsistencies and contradictions of Canadian refugee protection, ${ }^{14}$ both must navigate the precarious terrain of resettlement and "integration."

Drawing on the resettlement experiences of 17 separated children living in Canada, this article demonstrates the ways in which these youth traverse the complex, and at times hostile, terrain of resettlement. In so doing, the article critically engages with the discourses central to the discursive "making" of these youth. Instigated at the level of state policies and practices and propagated by the media, the meanings associated with these young people inevitably shape and inform how they are perceived, as well as the social contexts that they must adapt to. And yet, as we argue, the current popular, political, and, in some instances, academic representations of separated asylum-seeking and refugee children offer little insight into the complexity of their realities and experiences. Nor do they adequately reflect the thoughtful, tactical, and meaningful strategies and methods employed by these youth to cope with and resolve the many obstacles that they encounter during resettlement.

The article begins by tracing the academic and popular discourses and representations of refugee populations 
generally, and separated children specifically. Historically situated and reflected in state policy and practice, these discourses and representations emphasize the status of separated asylum-seeking and refugee children as both "victimized" and "troublesome" refugees and children. As a result, the ideological or discursive terrain that separated children must navigate is layered, often discordant, and precarious. Given the formulaic, yet contrastive portrayal of these youth, we draw upon the concept of social navigation. Through its emphasis on the tactical and, at times, unexpected ways in which individuals navigate circumstances beyond their control, the concept offers additional insight into the resettlement experiences of separated children by highlighting not only the discursive and material terrain these young people must contend with, but also the strategies they employ to do so. Following an overview of the study's methodology, we explore the creative, resourceful, and thoughtful ways in which the youth navigated the refugee determination system, experiences of discrimination, a lack of formalized support systems, and feelings of guilt during resettlement. These strategies challenge and defy archetypal representations and discourses pertaining to this group of young people.

\section{The Making of Refugees and Separated Children: Discourses of the Extreme}

The construction of refugees as inherently problematic has been prominent in historical and contemporary discussions. Early academic literature tended to depict refugees as "evil," carriers of disease, unruly, and immoral. ${ }^{15}$ Writing in 1912, Bryan noted in his discussion of Mexican immigrants to the United States, the "evils to the community at large which their presence in large numbers almost invariably brings." 16 A century later, the essence of the discourse has altered little. In their analysis of the discursive construction of refugees and asylum seekers in U.K. press articles published between 1996 and 2005, Gabrielatos and Baker argue that the conservative and tabloid British press have been responsible for creating and maintaining a moral panic around refugees and asylum-seekers. ${ }^{17}$ Baker and McEnery carried out an analysis of a corpus of British newspapers, as well as texts from the UNHCR website. ${ }^{18}$ The authors found quantitative evidence of linguistic patterns being repeatedly used in negative constructions of refugees. Refugees were described as "invaders" and "pests." Reflecting their dehumanization, refugees were also depicted as an elemental force-a natural disaster that cannot be reasoned with-frequently through the use of metaphors of water, floods, a dangerous mass, or a heavy load. Similarly, Esses found that media depictions of refugees constructed within frameworks of criminality in Canada engendered greater contempt of and suspicion toward refugees. ${ }^{19}$
In contrast to the depictions of refugees as "threatening" and "troublesome" is the portrayal of refugees as victims. Emphasizing their status as being irrevocably damaged and broken, refugees have been historically cast as wholly dependent, helpless, and victimized-ultimately deserving compassion and sympathy. In the aftermath of the Second World War, Siebold's depiction of the refugee follows closely with this construction: "The emaciated, hollow-eyed ragged victim of the concentration camp has replaced, in the mind's eye, the shawl-covered peasant of earlier days." 20 Lacking agency, the refugees' ability to function in society was viewed as ultimately compromised, and "the refugee identity had itself become a signifier for impairment."21 The image of the irrevocably damaged refugee continues to prevail. Baker and McEnery demonstrate that refugees are frequently presented as tragic victims or a collective group undergoing suffering. ${ }^{22}$ In the media, refugees are frequently reported as "starving, dying while locked in containers, seeking solace in religion, queuing for food, and being attacked by soldiers." 23

Perhaps not surprisingly, the constructions of separated children have tended to follow closely with negative depictions of refugees more generally. Embedded in overarching concerns with immigration control, there is a tendency amongst Western states to focus on the separated child's alien or irregular status: "Like adults, children are viewed as illegal migrants, who have chosen, or consented to, the evasion of immigration controls in order to gain access, who have lied, knowingly made use of false documents, who are coming to study or work without permission; from this point of view children's minority is a disqualification or, at best, an irrelevance." 24 Still, given the prevalence of child welfare discourse in Canada, a more sympathetic account of separated children does exist. Here, concerns over the protection of this particular group of refugees as children merges with discourses of vulnerability and deficiency. Located at the other end of the ideological spectrum, such accounts reflect refugee discourse more generally, as well as widely held constructions of children as dependent and in need of protection. Here, the focus is on emotional and developmental problems, post-traumatic stress, and psychosis. ${ }^{25}$

In both portrayals, the lives of separated children are decontextualized and essentialized. The representations are finite and cursory; they offer no attempt to capture or understand the complexity of the migration process, and the actual experiences of resettlement are obscured. Such representations easily generate archetypal images that eventually form an essential part of the public's conceptualization of the issues, thus perpetuating harmful stereotypes. ${ }^{26}$ And reflecting the power of popular discourse, they persist despite a growing body of available empirical evidence to 
the contrary. For example, Kohli observes that separated children are "elastic in their capacity to survive" and "do well at times of great vicissitude." 27 Similarly, Raghallaigh and Gilligan argue that the coping strategies of separated children are "purposefully chosen" according to what they believed "to be the most compelling options available in their circumstances." 28 Finally, in her work, Goodman emphasizes that despite the often harrowing experiences of flight and separation, the separated children in her sample displayed little sense of victimhood; rather, that they saw themselves as "survivors and agents of their future." 29

\section{Navigating Rough Terrain: The Lens of Social Navigation}

In light of the prevalence and endurance of negative depictions of separated asylum-seeking and refugee children, as well as their practical and material implications, a new way of documenting, analyzing, and understanding the realities and experiences of separated asylum-seeking and refugee children is required-one, as we have argued elsewhere, ${ }^{30}$ that is able to address and capture the agency and active decision-making processes of these youth, in tandem with the broader structural considerations that are intrinsic to the realities of flight and resettlement. The concept of "social navigation" offers insight into how this might be accomplished. Emphasizing capacity rather than victimhood, social navigation offers insight into how agents navigate social environments characterized by volatility and rapid social change. In such contexts new opportunities and unexpected obstacles frequently emerge, demanding the reconsideration of long-term goals and the development of new tactics and strategies. Social navigation thus represents the ability to plot, to actualize plotted trajectories, and to relate one's plots and actions to the constant possibility of change. It is, as Vigh writes, "the tactical movement of agents within a moving element; it is motion within motion." 31 This perspective is particularly useful when exploring the experiences of separated children, as it enables a greater focus on how these children manage within situations characterized by social flux and change. In previous work, we explored the concept of social navigation, as it relates to separated children and their experiences of flight. ${ }^{32}$ For participants, flight was, without question, marked by profound struggle, deprivation, and in many cases marred by violence and instability, yet, despite these conditions, our sample of youth consciously made tactical decisions and took calculated risks to ensure their survival and well-being. To further our analysis, in this article we apply the concept of social navigation to the resettlement experiences of these youth.

\section{Methodology}

Drawing on in-depth interviews and a focus group conducted by the authors with 17 separated children living in Canada, this analysis is part of a larger qualitative research project exploring the flight and resettlement experiences of separated children in Canada. All participants arrived in Canada under the age of 18, except for two who arrived in their 20s, but as children had fled unaccompanied to a country neighbouring their countries of origin. Of the 17 participants, 3 were female and 14 were male. This approximately reflects the percentages of female and male separated children seeking asylum in Canada. ${ }^{33}$ All respondents were over 18, except one who was 16 at the time of our initial interview and 17 at the time of our follow-up interview. Participants' countries of origin included Afghanistan, Angola, Ethiopia, Kenya, Nigeria, and Sudan. Data collection occurred in 2008-10, at which time the youth were living in Alberta, British Columbia, Manitoba, Ontario, and Quebec.

\section{Navigating Resettlement: Seeking Asylum and Settling in Canada}

Much like the terrain of flight, the terrain of resettlement is protracted and precarious. In addition to the challenges inherent in seeking asylum in a context increasingly suspicious of asylum-seekers, researchers and practitioners have found that upon resettlement to their host country, separated children frequently face psychosocial challenges, ${ }^{34}$ difficulties in school, ${ }^{35}$ and limited access to appropriate services. ${ }^{36}$ In 2005, the Standing Senate Committee on Human Rights noted that "migrant children [across Canada] face a number of obstacles to settlement ..., too often slipping through the cracks in service provision and education." 37 Our larger study found similar obstacles, including the challenges of facing a complicated refugee determination system, social isolation, economic hardship, feelings of guilt for having left loved ones behind in their countries of origin, and discrimination. ${ }^{38}$ Yet participants were in no way passive and instead engaged in a series of strategies to overcome these challenges. This section follows the trajectory of the youth interviewed from arrival to resettlement in order to illuminate the strategies employed by the youth to overcome the obstacles they faced overtime.

\section{Seeking Asylum in Canada: Navigating the Refugee Determination System}

For participants, the pathway to Canada varied. For those youth who declared themselves in Canada, the challenges of securing viable protection were often protracted and acute, situated in the increasingly politically reticent context of refugee status determination in Canada. In this 
context, as Macklin argues, the dichotomy of legal/illegal migrants is no longer based on motive but on the mode of entry; legal migrants are those who obtain permission to enter Canada prior to doing so, while illegal migrants are those who enter without permission. ${ }^{39}$ Regardless of the validity of an individual's claim for asylum, as soon as the border is circumvented she or he becomes an "illegal," warranting suspicion and harsh treatment, as opposed to compassion and protection. ${ }^{40}$ Despite their status as children, many of the youth who sought asylum in Canada where subjected to strict security measures: some were detained for extended periods of time, others had determination processes that extended well beyond the expedited timeline recommended for children, and still others had their claims for protection denied. Akin's and Manuel's narratives illustrate these outcomes. ${ }^{41}$

Akin fled Ethiopia for Europe at the age of 15 after his father was arrested on the grounds of his religious affiliation. Fearful of being sent back to Ethiopia if it was discovered that his parents were alive, he told officials that they were deceased-a lie he maintained while he was in Canada: "[Lying] affected my dignity, my confidence, my self-esteem ... It was a method of surviving. I hated it, but it was my only option. I considered it a life-and-death situation."

Contrary to Akin, Manuel engaged in a strategy of unmitigated trust and disclosure. Still, when he made himself known to officials, he was detained and his refugee determination process lasted nearly six years. During this time, Manuel relied heavily on a growing network of friends. He learned to speak, read, and write English. He graduated from high school. He found work. He started training for track and field. He strategically engaged in activities that fostered his integration, despite his precarious legal status. Eventually, Manuel's claim was accepted; Akin's was not.

Yet, when asked how he felt about the denial of his claim, Akin stated, "I felt very good; after that, things became more clear." Finally able to be himself, Akin employed a number of strategies to ensure his ongoing well-being, which included cultivating new relationships, working two jobs, attending university, and planning for the future. His claim for protection denied, he applied for permanent residency on humanitarian and compassionate grounds. This decision, however, was not about staying in Canada permanently, nor was it about benefiting from social services (which he no longer received). Rather it was about continuing his post-secondary and, in stark contrast to popular discourse, asserting his independence: "I work and pay my tuition whenever I can," he said. "When I can't, I use my credit card and then I pay it off. I don't consider myself as the government considers me, like some impotent refugee."
Akin's explicit rejection of anti-refugee discourse characterizes one of the ways in which a number of the youth navigated the discursive terrain of resettlement in Canada. Moreover, his narrative offers important insight into the internalization of victimizing discourses, and the concurrent contestation of those discourses, as well as the importance of distrust as a coping strategy. ${ }^{42}$ Lying, far from simply a strategy to circumvent borders and remain in Canada, was a method by which he felt he would become comprehensible to immigration authorities: "I had to lie," he stated, "because that's what they wanted to hear."

\section{Life in Canada: Navigating Permanent Resettlement}

For those fortunate enough to receive positive decisions, the refugee determination process represented a transition from claimant status to refugee status. In principle, this transition establishes the conditions through which refugees are able to participate more fully in Canadian society. Yet, as illustrated by participants' experiences, permanence does not always ensure that separated children are able to do so. Instead, many in our sample encountered a terrain of permanent resettlement characterized by pervasive discrimination, a lack of support, and ongoing conditions of poverty and underemployment. This section highlights the challenges faced by the youth and the strategies they employed to overcome them. These challenges included racialized discrimination, minimal formal support, profound social isolation, and poverty. In addition to these, the youth spoke of navigating and managing loss and separation, and struggling to attenuate feelings of guilt and remorse.

\section{Navigating Discrimination, Exclusion and Isolation}

The separated children interviewed reported experiencing high levels of exclusion and social isolation, marked by discrimination, a lack of formal support, un- and underemployment, and poverty. Yet as evident in their narratives, they were able to effectively redress these conditions through the development and implementation of strategies that were both multifaceted (remedying immediate conflict while establishing longer-term solutions) and multipurposed (resolving a number of obstacles or challenges simultaneously).

The discrimination encountered by the youth ranged from derogatory comments by service providers, including social workers, to racial profiling and verbal abuse at the hands of law enforcement officers. Reflecting patterns of racial profiling in Canada, ${ }^{43}$ while the former was a generalized experience shared by all of the youth, the latter was experienced more typically by male participants from Africa. Some of them, arbitrarily pulled over and accused of breaking the law, found that the frequency of these 
encounters required that they develop strategies to deal with police, sometimes daily. ${ }^{44}$

"I am from a country where if you are a police officer, you can do anything and get away with it," said Nijam. "So when the [police officer in Canada pulled me over] I didn't know that I could take it to court, that I could fight this guy, and that he would lose ... I was pretty mad, but I was like, if he's going to let me go, then it's just a matter of words."

Similarly, Edgard recollected, "[The police] pulled us over to give us a ticket ... They said I failed to wear a seat belt, but I was wearing my seat belt ... I tried to talk to them, but they didn't listen. So I went to my counsellor and my teacher, and they said we were going to fight it. I went to the court ... I told them what happened, and the [judge] was like, 'Oh, it sounds like you didn't do anything or anything bad,' so I shouldn't have gotten the ticket. So I didn't pay it. It was $\$ 247$. That's more than I make in two weeks."

Edgard, like many of the youth interviewed, relied on his network to navigate a system he was unfamiliar with. Yet not all youth were always inclined to do this. For example, Manuel recounted being pulled over by a police officer who referred to him as a "nigger" and "a dog" [sic]. When asked if he reported the incident, Manuel replied, "I guess back then I wasn't even a citizen, so I didn't want to."

Concurrently, the youth described more subtle forms of exclusion that they felt attributed to racialized stereotypes or misperceptions about refugees. Unlike with more hostile and potentially threatening encounters, the youth tended to interpret these experiences in terms of misunderstanding as opposed to more explicit and structural forms of racism. As Edgard recalled, "I told [my teacher] that it would be pretty good if [my classmates] knew who I was. I wanted them to know the things I had been through ... That's when they started to know me. They came to me and said, 'Oh, we thought that you were a bad person."'

Both Fatimah and Edgard engaged in strategies of disclosure. Sharing their experiences with their peers and teachers enhanced their relationships, facilitated acceptance, and opened them up to new possibilities. In these ways, sharing became a critical way of redressing gaps in formal support, which, following completion of the refugee determination, tended to be nominal. At the same time, as Edgard observed, disclosures helped to dispel the misperceptions about refugee youth. This was a prevalent theme in a number of youths' narratives, but particularly in Jean-Paul's.

Jean-Paul arrived in Canada after fleeing his native Sudan at the age of seven. Once in Canada and faced with an exceptionally precarious living situation characterized by poverty and lack of support, Jean-Paul cultivated as many connections as possible. In so doing, he became a visible and active presence in both his school and community, organizing events in support of refugee and youth-related issues, and soliciting help to fund the building of a school in his village of origin. He said, "I've spoken to many students [in Canada]. I go to different schools; they come to hear my story. Now, many schools have been raising money for my project. The point is not only money but to let people know that there are people within the community [who] live a hard life." He also drew a correlation between sharing and his activism: "[Telling people about my life] is hard, of course, but we need to change the way things are working, so I have to share it with people."

While most of the youth actively cultivated networks by openly sharing their stories, others preferred to keep their experiences of flight private. According to Manuel, "I don't like talking about [my life] too much because it's frustrating. One time I tried and people were like 'HUH?,' and then I was like, 'Forget it."' Hassan's experience was similar: "It's going to be meaningless and nobody is going to care. Telling my story is not going to change my life, so I just keep it to myself and move on like a regular Canadian boy." Ama reported, "I don't like to be too close to people. I don't trust anybody. I don't get close to people ... I don't talk to people."

For Manuel, silence represented a deliberate attempt to avoid reactions of disbelief, discomfort, pity, and indifference. For others, like Hassan, not opening up to other people about the experiences of flight represented a purposeful attempt to move forward. For others still, like Ama, a young woman from Nigeria, silence more closely paralleled what Papadopoulos calls "psychological hypothermia."45 As he points out, rather than being pathological, silence offers refugees a unique vantage point from which they can reflect on their experiences, assess their lives, and mourn for what they have lost. At the same time, and not unlike Manuel and Hassan, Ama strategically withdrew as a means of avoiding hurtful interactions, and implicitly her silence, like theirs, revealed significant distrust. Much like the use of silence, distrust was deliberately employed by many in the sample as a means of avoiding harm, betrayal, and disappointment.

Yet the youth were able to cultivate supportive networks, which assumed various forms. For those who engaged more openly, these networks tended to be more diversified, reflecting the range of people the youth came into contact with. For those who did not, these networks tended to include one or two trusted adults, typically a teacher or social worker, but mostly comprised other refugee youth.

In many cases, the youth reported not simply an affinity with other separated children, but a strong sense of collective identity that was drawn on to offset the challenges of resettlement. While the importance of group relationships was evident in the narratives of many respondents, nowhere 
was it more apparent than in the focus group conducted with six participants from Sudan.

Edgard remembered, "When I came here, I was having a hard time-you know, [how] can I survive? ... There were five of us who were living together in two bedrooms. [T] three of us were supporting [two] Lost Boys who were going to school. I don't know how we survived after we stopped getting support from the government."

Reflecting the multifaceted and multi-purposed nature of many of the methods of survival employed by the Sudanese youth, the cultivation of a collective identity represented a manifold strategy of support and network building, as well as what Raghallaigh and Gilligan identify as maintaining cultural continuity in a changed context. ${ }^{46}$

Hassan said, "Sharing is very important in our culture, as is getting together. I may have $\$ 15$, but it's our money; I will go buy something for us both to eat. Nobody is left behind." Peter's approach was similar: "It's like our culture back home. If somebody in a family works and has a good income, they take care of everyone else; that's how we carry on ... It's a good thing."

At the same time, the group dynamic of Sudanese participants interviewed was also a response to socio-economic conditions encountered in Canada. Chronically underemployed and unable to access formal state support, the Sudanese youth in our sample pooled their resources to ensure not only their daily survival, but for some (though not for all) the possibility of a different kind of future. While survival in Canada assumed a form very different from survival during flight, many of the Sudanese youth interviewed engaged in similar strategies of resource sharing.

\section{Navigating Separation and Loss}

Despite the extensive connections cultivated by most of the youth, many reported feeling a profound sense of loss, which they attributed to separation from family and community, and from significant support structures. The loss experienced by most of the youth, however, was often complicated by the conditions of flight. Unaware if parents and other family members were still alive, the majority of the youth struggled with profound uncertainty, which is reflected in what Boss has labelled "ambiguous loss." ${ }^{7}$ She writes, "With a clear-cut loss, there is more clarity-death certificate, mourning rituals, and the opportunity to honor and dispose of remains. With ambiguous loss, none of these markers exist. The clarity needed for boundary maintenance (in the sociological sense) or closure (in the psychological sense) is unattainable." 48 Navigating ambiguous loss entailed a number of strategies that simultaneously redressed other, though often related, challenges and issues. These strategies included the maintenance of cultural practice and language, religious belief, pursuing an education, and support of friends and family "left behind."

The maintenance of cultural practice and language served several purposes. In the first instance, representing a strategy of continuity, it offered a way of remaining connected to absent family and faraway places of origin. In the second instance, it grounded the youth, reminding them of where they came from, what they had endured, and what they were capable of surviving, and it motivated them, pushing them forward toward their envisioned futures. As Nijam explained, "The thing about language and culture is that they give us [some]thing that we can hold to, to be able to survive in any situation."

Hassan agreed: "I have to maintain [my language and culture], so when I go back to see my parents or relatives, I can go to them, I can talk to them, and they will listen to me. You don't have to throw it away. It makes me who I am, so I have to maintain it." As he explained, the maintenance of language and culture represented a means by which he would remain "knowable" to his family. A strategy of hope, his retention of language and culture mirrored his faith that he would one day be reunited with his family.

Religion represented another important method of coming to terms with loss and dealing with separation. At the same time, religion served as a link between life in Canada and life before and during flight and a way of remaining hopeful about the future. "If I survived all those miles, " said John, "not having food for extended period of time, why should I not pass these hard [university] classes, why should I not do well? Instead of getting down all the time about everything, it kind of assures me that I can do it. I feel like it made me a lot stronger, and I don't regret anything. It could be better, but only God knows the whole thing." Similarly, according to Edgard, "God will help me through the experience, and I will do what I need to do. And that's how I survive; I deal with things that happen."

Faith in God helped a number of the youth in our sample understand and accept the relative privilege they enjoyed in Canada.

Despite significant hardships, once in Canada, our participants often found themselves in situations where food insecurity was no longer an issue, and health care, education, and employment were now more accessible. Given their situations relative to those left behind, resettlement and the material security it offered often brought feelings of guilt when they thought of their loved ones who continued to suffer: "In Canada you are free, but not entirely free," said Amsalu. "It's like 50/50 because of the family you are missing, what you wish you could do for the people left behind."

It was much the same for Nijam: "When your people are struggling, you can never feel at home. [In Canada] if 
you have good credit, you can go to a bank and loan some money to buy a nice house. But I would not like a nice house, because when I imagine where I was-and that my brothers and sisters are still living there ... How hard the life is back home still affects us here. Even though it's thousands of miles away, it still affects our lives. When you budget, you figure out you have a couple extra bucks, and you imagine the life that we were living when we were there, and you cannot close your eyes, you cannot not send something."

As a strategy, however, remittance sending was not without its challenges. While mitigating some of the guilt associated with resettlement as well as the anxiety concerning the well-being of friends and family, assuring regular support required considerable sacrifice. This was largely compounded by the kinds of work the youth were typically able to access. Part-time and low-paid, the conditions of employment in Canada necessitated that many of the youth work two or more jobs in order to meet their needs, in addition to those of friends and family.

As Peter described it, "One job is nothing. It wouldn't pay my rent [in Canada] and [my wife's] rent in Nairobi, my food and her food, so I have to have two jobs ... I go to school full-time and have full-time work. I sleep for two and a half hours every day because I have to get it done. With full-time school and a part-time job, I wouldn't be able to handle [all the expenses]."

Pursuing an education was both a short-term and a longterm strategy. Many of the youth approached the daily tasks associated with school-going to class, completing assignments-as a distraction from the loneliness of separation and the hardships of life in Canada. At the same time, all of the youth who were able to attend school applied themselves in earnest, with the intention of eventually securing wellpaid work that would allow them to help family abroad, and in some instances, maybe be reunited. Fatimah, for example, arrived in Canada through World University Services of Canada. Although she was scared to leave her family, she strongly felt that access to Canadian post-secondary education would improve her life and theirs: "I didn't have a choice, because I wanted a better education. I knew that if I came to Canada and got a good education, I might have a chance, [that] maybe I would get a chance to bring my parents here to come and stay with me someday."

While Fatimah's situation was unique, all of the youth spoke of the value of education and its transformative possibilities. In addition to the immediate financial support provided to family, a number of the youth hoped to achieve broad structural changes in their countries of origin. JeanPaul raised awareness about the situation in Sudan, Osman hoped to focus on international development studies in university, and still others hoped to return to their countries of origin following completion of their education. In these ways, the opportunity to provide assistance to family, friends, and community meant that their suffering-manifest in the physical struggles of flight, the emotional challenges of separation, and the difficulties of life in Canada-was not in vain.

\section{Conclusion}

Seen as deviating from the normative category of "Canadian" and from the increasingly idealized category of economically viable and 'contributing' immigrant, ${ }^{49}$ many of the youth in our sample experienced Canada as a capricious and perilous terrain that required careful navigation. By encouraging a nuanced exploration of how this navigation occurs, the social navigation framework at once recognizes the discursive structures and material processes that inform the context of resettlement, while acknowledging the creative efforts of separated asylum-seeking and refugee youth to circumvent (albeit at times subtly and not always permanently) those structures and processes.

Effectively bringing into focus the intersection of agency and structure, the framework also facilitates a more nuanced understanding of actions that might otherwise appear problematic. Altering their stories, for example, represented a critical strategy for several of the youth both in the context of flight and resettlement. Social navigation complicates and contextualizes this behaviour: it is not simply the mainstay of a "bogus" refugee claim, nor is it the posturing of a fraudulent claimant; rather, it is an effort on the part of an individual, who responding to a context increasingly characterized by hostility and suspicion, acts and reacts to ensure survival.

Set against the structural realities of nominal support, discrimination, and exclusion, and alongside the sense of loss that characterizes flight and separation, life in Canada necessitated the development of strategies at arrival and throughout the resettlement process. These strategies were varied, multifarious, and complex, so that frequently they converged and coalesced, redressing multiple conditions of resettlement simultaneously. In regards to the refugee determination process, some youth engaged in strategies of unmitigated trust, while others were more guarded or, responding to the structural biases within the refugee determination system, altered their stories in ways they believed would ensure their safety. These strategies of openness and trust, and of silence and distrust were equally present throughout the resettlement process, as the youth assessed and reassessed those around them, seeking out supportive people while avoiding hurtful interactions. Yet, reflecting the complexity of their strategies, rather than signalling 
passivity or pathology, silence and distrust were, in fact, thoughtful and adaptive expressions of agency.

In a similar vein, a number of the youth sought out and cultivated group identities that helped to mitigate the emotional and material challenges of life in Canada. These youth pooled their resources and offered each other ongoing support. All of the youth spoke of the importance of language, culture, and religion. These reflected, among other things, a continuing connection to countries of origin and to families and other significant people "left behind." This connection was also realized in more direct ways, as most of the youth sent remittances to the country of origin as well as to the refugee camps where they had lived. In this way, they came to understand their experiences of flight (so often rooted in violence, insecurity, and scarcity) and resettlement (marked by isolation, loneliness, and struggle) as essential facets of who they were, what they were capable of, and who they would become. Their ability to provide short-term assistance and to work toward sustainable change validated these difficult experiences, made them valuable (though no less painful), and propelled the youth forward.

\section{Notes}

1. K. R. Good, Municipalities and Multiculturalism: The Politics of Immigration in Toronto and Vancouver (Toronto, ON: University of Toronto Press, 2009), 103.

2. Citizenship and Immigration, "Legislation to Protect Canada's Immigration System Receives Royal Assent," news release, 29 June 2012, http://www.cic.gc.ca/english/ department/media/releases/2012/2012-06-29.asp.

3. M. Foucault, Power/Knowledge: Selected Interviews and Other Writings, 1972-1977, ed. C. Gordon (Brighton: Harvester, 1980).

4. D. Kellner, Media Culture: Cultural Studies, Identity and Politics between the Modern and the Post-Modern (London: Routledge, 1995).

5. V. Burr, An Introduction to Social Constructivism (New York: Routledge, 1995).

6. Y. Park, "Making Refugees: A Historical Discourse Analysis of the Construction of the 'Refugee' in US Social Work," British Journal of Social Work 38 (2008): 771-87.

7. Kellner, Media Culture, 5.

8. P. Baker and T. McEnery, "A Corpus-Based Approach to Discourses of Refugees and Asylum Seekers in UN and Newspaper Texts," Journal of Language and Politics 4, no. 2 (2005): 197-226, doi:10.1075/jlp.4.2.04bak.

9. C. Bryan and M. Denov, "Separated Children in Canada: The Construction of Risk Identity," Journal of Immigrant \& Refugee Studies 9, no. 3 (2011): 242-66, doi:10.1080/15562 948.2011.592806.
10. W. Ayotte, Separated Children Seeking Asylum in Canada (Ottawa: United Nations High Commissioner on Refugees, 2001), 6.

11. UNHCR, "Information: Impact of Armed Conflict on Children," n.d., http://www.unicef.org/graca/alone.htm.

12. CBC News, "Unaccompanied Child Refugees Pouring into Canada," 28 July 2013, http://www.cbc.ca/news/canada/unaccompanied-child-refugees-pouring-into-canada-1.1328888.

13. A. Macklin, "Disappearing Refugees: Reflections on the US-Canada Safe Third Party Agreement," Columbia Human Rights Law Review 36 (2005): 365-426.

14. J. Bhabha, "Minors or Aliens: Inconsistent State Intervention and Separated Child Asylum-Seekers," European Journal of Migration and Law 3 (2001): 293.

15. M. Kamphuis and M. Gleisner, "Social Work in Postwar Holland," Journal of Social Casework 28, no. 7 (1947): 24353; E. Zwerdling and G. Polansky, "Foster Home Placement of Refugee Children," Journal of Social Casework 30, no. 7 (1949): 277-82.

16. S. Bryan, "Mexican Immigrants in the United States," Survey 28 , no. 23 (1912): 730.

17. C. Gabrielatos and P. Baker, "Fleeing, Sneaking, Flooding: A Corpus Analysis of Discursive Constructions of Refugees and Asylum Seekers in the UK Press, 1996-2005," Journal of English Linguistics 36, no. 1 (2008): 5-38.

18. Baker and McEnery, "Corpus-Based Approach."

19. V. M. Esses, S. Veenvliet, G. Hodson, and L. Mihic, "Justice, Morality, and the Dehumanization of Refugees," Social Justice Research 21 (2008): 4-25.

20. J. Siebold, "Helping New Americans," Journal of Social Casework 30, no. 2 (1949): 71-2.

21. Park, "Making Refugees," 781.

22. Baker and McEnery, "Corpus-Based Approach."

23. Ibid., 206.

24. J. Bhabha, "Minors or Aliens: Inconsistent State Intervention and Separated Child Asylum-Seekers," European Journal of Migration and Law 3 (2001): 293.

25. See P. L. Geltman, W. G. Knight, and H. Ellis, “The 'Lost Boys' of Sudan: Use of Health Services and Functional Health Outcomes of Unaccompanied Refugee Minors Resettled in the U.S," Journal of Immigrant and Minority Health 10, no. 5 (October 2008): 389-96, doi:10.1007/s10903-0079110-6; M. Hodes, D. Jagdey, N. Chandra, and A. Cunniff, "Risk and Resilience for Psychological Distress amongst Unaccompanied Asylum Seeking Adolescents," Journal of Clinical Psychology and Psychiatry 49, no. 7 (2008): 723-32; S. L. Lustig, M. Kia-Keating, W. Grant Knight, L. Geltman, H. Ellis, J. D. Kinzie, T. Keane, and G. N. Saxe, "Review of Child and Adolescent Refugee Mental Health," Journal of the American Academy of Child and Adolescent Psychiatry 43, no. 1 (2004): 24-36; A. Sourander, "Behavior Problems and Traumatic Events of Unaccompanied Refugee Minors," Child Abuse and Neglect 22, no. 7 (1998): 719-27. 
26. M. Denov, "Child Soldiers and Iconography: Portrayals and (Mis)representations," Children \& Society 26, no. 4 (2012): 280-92, doi:10.1111/j.1099-0860.2010.00347.x; L. Macmillan, "The Child Soldier in North-South Relations," International Political Sociology 3 (2009): 36-52.

27. R. Kohli, "The Comfort of Strangers: Social Work Practice with Unaccompanied Asylum Seeking Children and Young People in the UK," Child and Family Social Work 11 (2006): 7.

28. M. N. Raghallaigh and R. Gilligan, "Active Survival in the Lives of Unaccompanied Minors," Child \& Family Social Work 15 (2010): 233.

29. J. H. Goodman, "Coping with Trauma and Hardship among Unaccompanied Refugee Youths from Sudan," Qualitative Health Research 14, no. 9 (2004): 1182.

30. M. Denov and C. Bryan, "Tactical Maneuvering and Calculated Risks: Independent Child Migrants and the Complex Terrain of Flight," New Directions for Child and Adolescent Development 136 (2012): 13-27, doi:10.1002/cad.20008.

31. H. Vigh, Navigating Terrains of War: Youth Soldiering in Guinea-Bissau (New York: Berghahn Books, 2006), 131.

32. Denov and Bryan, "Tactical Maneuvering.

33. Citizenship and Immigration Canada, Annual Report to Parliament on Immigration, 2008 (Ottawa, ON: Citizenship and Immigration Canada, 2008), http://www.cic.gc.ca/ English/resources/publications/annual-report2008/.

34. L. Halcón, C. Robertson, and K. Savik, "Trauma and Coping in Somali and Oromo Refugee Youth," Journal of Adolescent Health 35, no. 1 (2004): 17-25; L. McCloskey and K. Southwick, "Psychosocial Problems in Refugee Children Exposed to War," Pediatrics 97, no. 3 (1996): 394-97.

35. M. Kia-Keating and B. H. Ellis, "Belonging and Connection to School in Resettlement: Young Refugees, School Belonging, and Psychosocial Adjustment," Clinical Child Psychology and Psychiatry 12, no. 1 (2007): 29-43.

36. N. Davidson, S. Skull, D. Burgner, P. Kelly, S. Raman, D. Silove, Z. Steel, R. Vora, and M. Smith, "An Issue of Access: Delivering Equitable Health Care for Newly Arrived Refugee Children in Australia," Journal of Paediatrics and Child Health 40, nos. 9-10 (October 2004): 569-75, doi:10.1111/ j.1440-1754.2004.00466.x; H. Ngo, "Patchwork, Sidelining and Marginalization: Services for Immigrant Youth," Journal of Immigrant \& Refugee Studies 7, no. 1 (2009): 82-100. language and financial constraints, lack of awareness of available services, and lack of health provider understanding of the complex health concerns of refugees can all contribute to limiting access to health care. Understanding the complexities of a new health care system under these circumstances and finding a regular health provider may be difficult. In some cases there may be a fundamental distrust of government services. The different levels of health entitlements by visa category and (for some
37. Cited in S. Crowe, Immigrant and Refugee Children in Middle Childhood (Ottawa, ON: National Children's Alliance, 2006), 12.

38. Bryan and Denov, "Separated Children in Canada"; M. Denov and C. Bryan, "Unaccompanied Refugee Children in Canada: Experiences of Flight and Resettlement," Canadian Social Work 12, no. 1 (2010): 67-75.

39. A. Macklin, "Disappearing Refugees: Reflections on the US-Canada Safe Third Party Agreement," Columbia Human Rights Law Review 36 (2005): 365-426.

40. A. Mann, "Refugees Who Arrive by Boat and Canada's Commitment to the Refugee Convention," Refuge 26, no. 2 (2011): 191-206.

41. In order to protect participant confidentiality and anonymity, pseudonyms are used throughout when referring to or citing participants.

42. Raghallaigh and Gilligan, "Active Survival in the Lives of Unaccompanied Minors."

43. S. Wortley and J. Tanner, "Data, Denials and Confusion: The Racial Profiling Debate in Toronto," Canadian Review of Policing Research 1, no. 2004 (2004): 367-90; S. Wortley and J. Tanner, "Inflammatory Rhetoric? Baseless Accusations? Responding to Gabor's Critique of Racial Profiling Research in Canada," Canadian Journal of Criminology 47, no. 3 (2005): 581-609.

44. See Bryan and Denov, "Separated Children in Canada."

45. R. K. Papadopoulos, Therapeutic Care for Refugees: No Place Like Home, Tavistock Clinic Series (London: Karnac, 2002).

46. Raghallaigh and Gilligan, "Active Survival in the Lives of Unaccompanied Minors."

47. P. Boss, Ambiguous Loss (Cambridge, MA: Harvard University Press, 1999); Boss, "Ambiguous Loss Research, Theory, and Practice: Reflections after 9/11, Journal of Marriage and Family 66 (2004): 551-66; Boss, Loss, Trauma, and Resilience: Therapeutic Work with Ambiguous Loss (New York: W. W. Norton, 2006).

48. Boss, “Ambiguous Loss Research," 553.

49. Bryan and Denov, "Separated Refugee Children in Canada."

Myriam Denov is a James McGill Professor in the School of Social Work at McGill University. The author may be contacted atmyriam.denov@mcgill.ca.

Catherine Bryan is a PhD candidate the Department of Sociology and Social Anthropology at Dalhousie University. The author may be contacted at c.bryan@dal.ca. 